\title{
Voltage Stability Improvement using STATCOM and SVC
}

\author{
Anwar S. Siddiqui \\ Jamia Millia Islamia \\ New Delhi, India
}

\author{
Tanmoy Deb \\ Jamia Millia Islamia \\ New Delhi, India
}

\begin{abstract}
Voltage stability of a system is affected by reactive power limit of the system. FACTs devices improve the reactive power flow in system thereby improving voltage stability. This paper explores the effect of SVC and STATCOM on static voltage stability. IEEE- 14 bus system has been used to demonstrate the ability of SVC and STATCOM in improving the voltage stability margin. These FACTs controllers help to increase the load ability margin of the power network.
\end{abstract}

\section{Keywords}

SVC, STATCOM, Voltage stability

\section{INTRODUCTION}

With deregulation of electricity markets worldwide, there are good number of market players trying to engage in power buying and selling business. The sudden increase in peak demand and power transfer affects voltage security. In some of the incidents, voltage collapse was responsible for the outage. One of the major reasons for voltage instability is reactive power imbalance in the system[1]. This directly affects the load ability of a bus in a power network. In order to prevent a voltage collapse when system approaches load ability limit, a local reactive power support can immediately provide relief and enhance static voltage stability. The gradual change in power system lead to shortage of reactive power leading to reduce power stability. With increased power flow, there is corresponding decrease in voltage at the bus. Further increase in loading leads to shortage of reactive power. Thereafter, any further increase in active power transfer causes a quick decrease in magnitude of voltage of the bus. As the critical point is reached, heavy reactive power losses lead to a high voltage drop and there voltage collapse takes place. To prevent the system, reaching this state is to augment reactive power support or cut-off reactive power demand[2]. This phenomenon sometimes leads to major black-out [3].

One of the methods to overcome this problem is to place reactive power support on the weakest bus 9 bus having lowest margin or near the collapse point).

FACTs devices- SVC and STATCOM can provide reactive power support. The effect of SVC and TCSC on voltage collapse has been studied by Canizares and Faur[4]. A. Kazemi et al studied the voltage stability using STATCOM and UPFC controllers[5].

C.R. Fuerte Esquivel[7] used Newton Raphson algorithm for power flow control has been used in this paper. This paper studies effects of SVC and STATCOM on voltage stability improvement. The paper is organized as- section-2 deals with mathematical modeling of SVC \& STATCOM. Section-3 provides results and discussion. Conclusion is given in Section-4.

\section{MODELING OF FACTS CONTROLLER}

\subsection{SVC}

SVC is a parallel connection of fixed capacitor and thyristor controlled reactor (TCR). TCR consists of a fixed inductor and a bi-directional thyristor valve. The thyristors are fixed symmetrically in an angle range of 900 to 1800 w.r.t. SVC voltage.

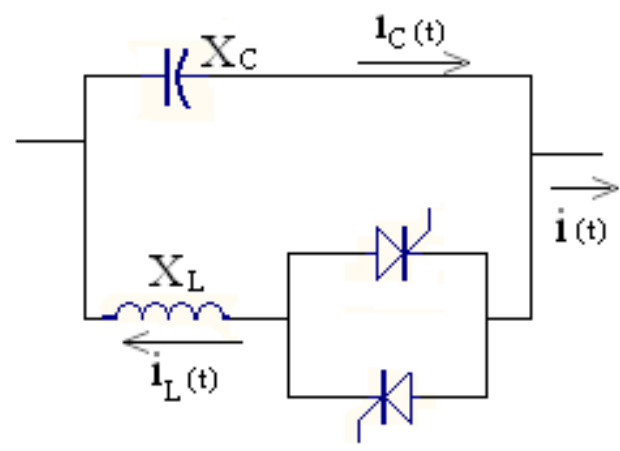

Fig 1 Circuit of SVC

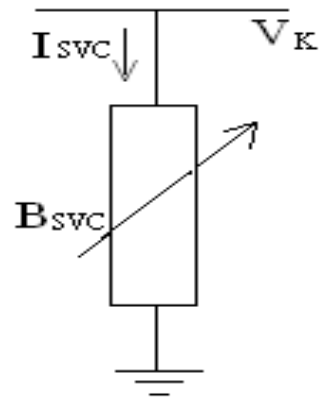

Fig 2 Equivalent circuit of SVC

Current drawn by SVC,

$\mathrm{I}_{S V C}=j B_{S V C} V_{K}$

Reactive power drawn by SVC,

$Q_{K}=Q_{S V C}=-V_{K}^{2} B_{S V C}$

The positive sequence susceptance of SVC consisting of TCR of inductance $\mathrm{XL}$ and with shunt capacitance $\mathrm{Xc}$ is given by [7],

$\mathrm{B}_{\mathrm{SVC}}=\mathrm{B}_{\mathrm{c}}-\mathrm{B}_{\mathrm{TCR}}=\frac{1}{X C X L}\left[X L-\frac{X C}{\pi}[2(\pi-d)+\sin 2 \alpha]\right]$

Substituting above eq. in eq. (1).

$\mathrm{Q}_{\mathrm{K}}=\frac{-V K 2}{X L X C}\left\{\left[X L-\frac{X C}{\pi}[2(\pi-\alpha S V C)+\sin (2 \alpha S V C]\}\right.\right.$ 
From above equation, the linearized SVC equation is given as-

$$
\left[\begin{array}{l}
\Delta P k \\
\Delta Q K
\end{array}\right] i=\left[\begin{array}{cc}
0 & 0 \\
0 & \frac{2 V 2}{\pi X L}[\cos (2 \alpha S V C)-1
\end{array}\right] i\left[\begin{array}{c}
\Delta \theta K \\
\Delta \alpha S V C
\end{array}\right] i
$$

At the end of iteration (i), the variable firing angle $\alpha_{S V C}$ is updated as

$\alpha_{\mathrm{SVC}}{ }^{\mathrm{i}}=\alpha_{\mathrm{SVC}}{ }^{\mathrm{i}-1}+{ }^{\Delta} \alpha \mathrm{SVC}$

\subsection{STATCOM}

A STATCOM is a voltage source inverter which converts DC input voltage into $\mathrm{AC}$ output voltage by which it regulates active and reactive power in the system. The AC voltage is controllable both in magnitude and phase. It can exchange active power if energy source is added on DC side.

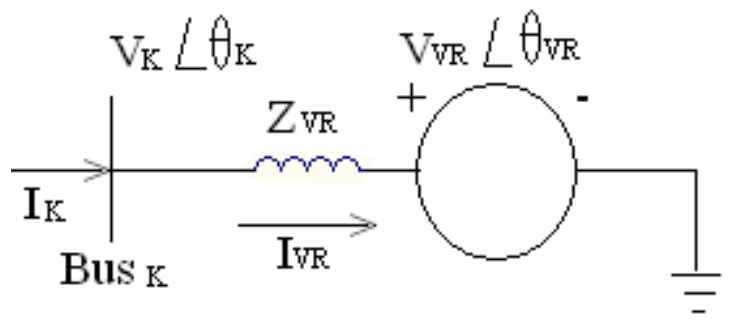

Fig 3 Equivalent circuit of STATCOM

Unlike SVC, STATCOM is represented as a voltage source for the full range of operation, enabling a better voltage support.

The power flow equation are given by-

$$
\mathrm{E}_{\mathrm{VR}}=\mathrm{V}_{\mathrm{VR}}\left(\cos \delta_{\mathrm{VR}}+\mathrm{j} \sin \delta_{\mathrm{VR}}\right)
$$

Based on shunt connection-

$$
\mathrm{S}_{\mathrm{VR}}=\mathrm{V}_{\mathrm{VR}} \mathrm{I}_{\mathrm{VR}}{ }^{*}=\mathrm{V}_{\mathrm{VR}} \mathrm{Y}_{\mathrm{VR}}{ }^{*}\left(\mathrm{~V}_{\mathrm{VR}}{ }^{*}-\mathrm{V}_{\mathrm{K}}{ }^{*}\right)
$$

Following active and reactive power equations can be obtained for the converter and the bus $\mathrm{K}$ respectively.

$P_{V R}=V_{V R}^{2} G_{V R}+V_{V R} V_{K}\left[G_{V R} \cos \left(\delta_{V R}-\theta_{K}\right)+B_{V R} \sin \left(\delta_{V R}-\theta_{K}\right)\right]$

$\mathrm{Q}_{\mathrm{VR}}=-\mathrm{V}_{\mathrm{VR}}^{2} \mathrm{~B}_{\mathrm{VR}}+\mathrm{V}_{\mathrm{VR}} \mathrm{V}_{\mathrm{K}}\left[\mathrm{G}_{\mathrm{VR}} \sin \left(\delta_{\mathrm{VR}}-\theta_{\mathrm{K}}\right)+\mathrm{B}_{\mathrm{VR}} \cos \left(\delta_{\mathrm{VR}}-\theta_{\mathrm{K}}\right)\right]$

$\mathrm{P}_{\mathrm{K}}=\mathrm{V}_{\mathrm{K}}^{2} \mathrm{G}_{\mathrm{VR}}+\mathrm{V}_{\mathrm{VR}} \mathrm{V}_{\mathrm{K}}\left[\mathrm{G}_{\mathrm{VR}} \cos \left(\theta_{\mathrm{K}^{-}} \delta_{\mathrm{VR}}\right)+\mathrm{B}_{\mathrm{VR}} \sin \left(\theta_{\mathrm{K}^{-}} \delta_{\mathrm{VR}}\right)\right]$

$\mathrm{Q}_{\mathrm{K}}=-\mathrm{V}_{\mathrm{K}}^{2} \mathrm{~B}_{\mathrm{VR}}+\mathrm{V}_{\mathrm{VR}} \mathrm{V}_{\mathrm{K}}\left[\mathrm{G}_{\mathrm{VR}} \sin \left(\theta_{\mathrm{K}}-\delta_{\mathrm{VR}}\right)-\mathrm{B}_{\mathrm{VR}} \cos \left(\theta_{\mathrm{K}^{-}} \delta_{\mathrm{VR}}\right)\right]$
Using these equations, linearized STATCOM model is given below, where voltage $V_{V R}$ and phase angle $\delta_{V R}$ are taken as state variable.

$$
\left[\begin{array}{c}
\Delta P k \\
\Delta Q K \\
\Delta P V R \\
\theta V R
\end{array}\right]=\left[\begin{array}{ll}
\frac{\partial P K}{\partial \theta K} \frac{\partial P K}{\partial V K} V K & \frac{\partial P K}{\partial \delta V R} \frac{\partial P K}{\partial \delta V R} V V R \\
\frac{\partial Q K}{\partial \theta K} \frac{\partial Q K}{\partial V K} V K & \frac{\partial Q K}{\partial \delta V R} \frac{\partial Q K}{\partial \delta V R} V V R \\
\frac{\partial P V R}{\partial \theta K} \frac{\partial P V R}{\partial V K} V K & \frac{\partial P V R}{\partial \delta V R} \frac{\partial P V R}{\partial \delta V R} V V R \\
\frac{\partial Q V R}{\partial \theta K} \frac{\partial Q V R}{\partial V K} V K & \frac{\partial Q V R}{\partial \delta V R} \frac{\partial Q V R}{\partial \delta V R} V V R
\end{array}\right]\left[\begin{array}{c}
\Delta \theta K \\
\frac{\Delta V K}{V K} \\
\Delta \delta V R \\
\frac{\Delta V V R}{V V R}
\end{array}\right]
$$

\section{RESULT \& DISCUSION}

IEEE-14 bus system is used for voltage stability analysis.

With the objective to bring the bus voltage to $1 \mathrm{pu}, \mathrm{SVC}$ and SATCOM are implemented in the test system.

Table no. 3.1 and 3.2 shows the power flow result on implementation of SVC and STATCOM on IEEE-14 bus system. The table 3.1 show reactive power supplied by SVC, firing angle, bus voltage, SVC suceptance and corresponding total PQ losses.

The table 3.2 shows, reactive power supplied by STATCOM, bus voltage, source voltage and angle and total PQ losses.

(i) It is observed that source voltage

Magnitude of STATCOM is greater than unity for raising the bus voltage to $1 \mathrm{pu}$ and less then unity for lowering it to $1 \mathrm{pu}$. Also, more the difference between base case bus voltage and $1 \mathrm{pu}$, more is the source voltage magnitude and of STATCOM and vice- versa.

(ii) The bus voltage are controlled by SVC and STATCOM. On the comparison of these devices for the same pre-specified voltage at the bus it is concluded that reactive power supplied by STATCOM is more in comparison to the reactive power supplied by SVC. This characteristics make STATCOM more robust and effective than SVC in providing voltage support and stability improvement.

(iii)For control of pre-specified voltage at the bus, SVC and STATCOM are good option. But the choice of STATCOM is better because it delivers more reactive power than SVC for identical voltage control requirement.

(iv)STATCOM has a faster response as it has no time delay connected with firing of thyristor. However, STATCOM is costlier than SVC.

\section{CONCLUSION}

A comparative analysis of SVC and STATCOM in static voltage stability enhancement is presented. Both, SVC and STATCOM improve static voltage of the buses. STATCOM provides higher reactive power support with a faster response time but is expensive. SVC, on the other hand, is a cheaper substitute with relatively longer response time. But being capacitor based, the reactive power support to bus falls significantly at the time of fault. Hence, STATCOM provides a robust option. Hence comparison indicates STATCOM is suitable for static as well as dynamic voltage restotration.

\section{REFERENCES}

[1] N. Taleb, M. Ehsan, S.M.T. Bathace, May 2004 , "Effects of SVC and TCSC control strategies on static voltage collapse phenomenon", IEEE proceeding, south east con. pp. 161-168. 
[2] ArthitSode-yome, Nadara jk Mithilananthan and Kwang Y.Lee,2005, "Static voltage stability Margin Enhancement Using STATCOM, TCSC, and SSSC", IEEE/PES Transmission and Distribution conference and Exhibition, Asia and Pacific, Dalian chine.

[3] R. Natesan and G. Radman, 2004, " Effects of STATCOM.SSSC and UPFC on Voltage Stability", Proceeding of the system theory thirty-sixth southeastern symposium, pp. 546-550.

[4] C.A Canlzares, Z.T. Faur, Feb 1999, "Analysis of SVC and TCSC Controllers in voltage collapse", IEEE trans. Power system, vol.14, No.1, pp.158-165.
[5] A.Kazemi, V.Vahidinasab and A.Mosallanejad, Nov 2829, 2006," study of STATCOM and UPFC controllers for voltage stability Evaluated by Saddle-Node Bifurcation Analysis", First International Power and Energy Conference PE Con/IEEE, Putrajaya, Malaysia,.

[6] F.Milano, July 14, 2005, " Power System Analysis Toolbar", version 1.3.4, Software and Documentation.

[7] C.R. Fuerte Esquirel, E.Acha, Nov,1997, " A Newton type algorithm for control of power flow in Electrical network", IEEE trans. On PS, vol.12, Issue 4, pp.14741480 .

Table No. 1 Power flow result for SVC

\begin{tabular}{|c|c|c|c|c|c|c|}
\hline \multirow{2}{*}{$\begin{array}{l}\text { Bus } \\
\text { No. }\end{array}$} & \multirow{2}{*}{$\begin{array}{l}\text { Base } \\
\text { Case } \\
\text { Voltage } \\
(\mathrm{pu})\end{array}$} & \multicolumn{3}{|c|}{ With SVC } & \multirow[b]{2}{*}{$\begin{array}{l}\text { Firing angle } \\
\text { (deg) }\end{array}$} & \multirow[b]{2}{*}{$\begin{array}{l}\text { Total PQ loss } \\
(\mathrm{pu})\end{array}$} \\
\hline & & $\begin{array}{l}\text { Voltage } \\
(\mathrm{pu})\end{array}$ & $\begin{array}{l}\text { Reactive } \\
\text { Power } \\
\text { Supplied } \\
\text { By SVC } \\
\text { (pu) }\end{array}$ & $\begin{array}{l}\text { SVC } \\
\text { Suceptance } \\
\text { (pu) }\end{array}$ & & \\
\hline 11 & 0.9679 & 1.0000 & -0.1732 & 0.1732 & 131.7971 & $\begin{array}{l}0.1521- \\
\text { j0.1473 }\end{array}$ \\
\hline 12 & 0.9703 & 1.0000 & -0.1233 & 0.1233 & 130.6298 & $\begin{array}{l}0.1528- \\
\text { j0.1506 }\end{array}$ \\
\hline 13 & 0.9642 & 1.0000 & -0.2696 & 0.2696 & 134.1282 & $\begin{array}{l}0.1527- \\
\text { j0.1497 }\end{array}$ \\
\hline 14 & 0.9417 & 1.0000 & -0.2398 & 0.2398 & 133.3866 & $\begin{array}{l}0.1527- \\
\text { j0.1455 }\end{array}$ \\
\hline
\end{tabular}

Table no. 2 Power flow result for STATCOM

\begin{tabular}{|c|c|c|c|c|c|c|}
\hline \multirow{2}{*}{$\begin{array}{l}\text { Bus } \\
\text { No. }\end{array}$} & \multirow{2}{*}{$\begin{array}{l}\text { Base } \\
\text { Case } \\
\text { Voltage } \\
(\mathrm{pu})\end{array}$} & \multicolumn{5}{|c|}{ With SATCOM } \\
\hline & & $\begin{array}{l}\text { Voltage } \\
\text { (pu) }\end{array}$ & $\begin{array}{l}\text { Reactive } \\
\text { Power } \\
\text { Supplied } \\
\text { By SVC } \\
\text { (pu) }\end{array}$ & $\begin{array}{l}\text { SVC } \\
\text { Suceptance } \\
\text { (pu) }\end{array}$ & $\begin{array}{l}\text { Source } \\
\text { voltage } \\
\text { and angle } \\
\text { (pu) }\end{array}$ & $\begin{array}{l}\text { Total PQ loss } \\
(\mathrm{pu})\end{array}$ \\
\hline 11 & 0.9679 & 1.0000 & -0.1732 & 0.1762 & $\begin{array}{l}1.0173 \\
-0.2836 \\
\end{array}$ & $0.1527-\mathrm{j} 0.1497$ \\
\hline 12 & 0.9703 & 1.0000 & -0.1233 & 0.1238 & $\begin{array}{l}1.0122 \\
-0.2954\end{array}$ & $0.1528-\mathrm{j} 0.1506$ \\
\hline 13 & 0.9642 & 1.0000 & -0.2696 & 0.2768 & $\begin{array}{l}1.0270 \\
-0.2971\end{array}$ & $0.1527-\mathrm{j} 0.1497$ \\
\hline 14 & 0.9417 & 1.0000 & -0.2398 & 0.2455 & $\begin{array}{l}1.0240 \\
-0.3175\end{array}$ & $0.1527-\mathrm{j} 0.1455$ \\
\hline
\end{tabular}




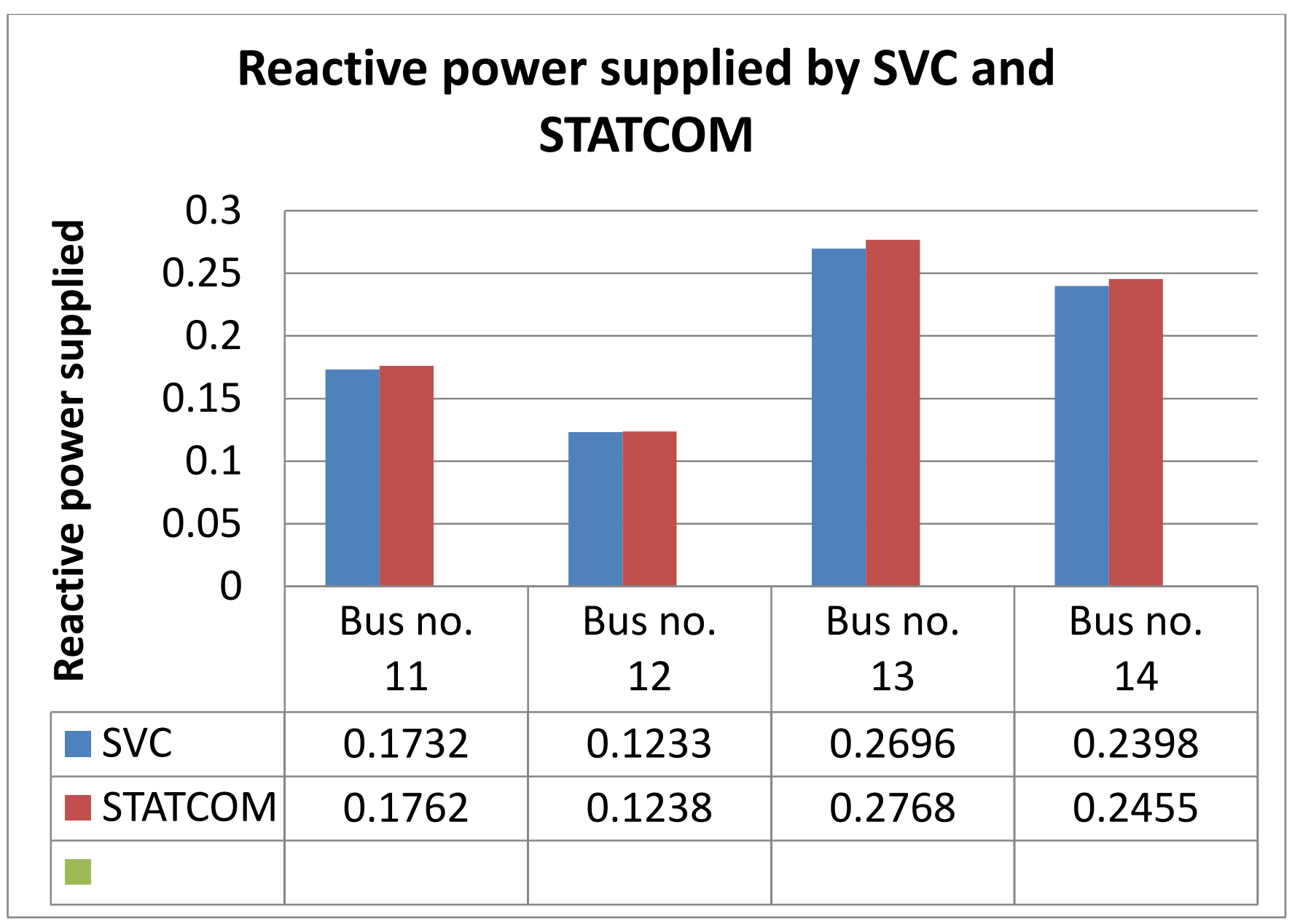

Figure 3.1 Reactive power supplied by SVC and STATCOM 


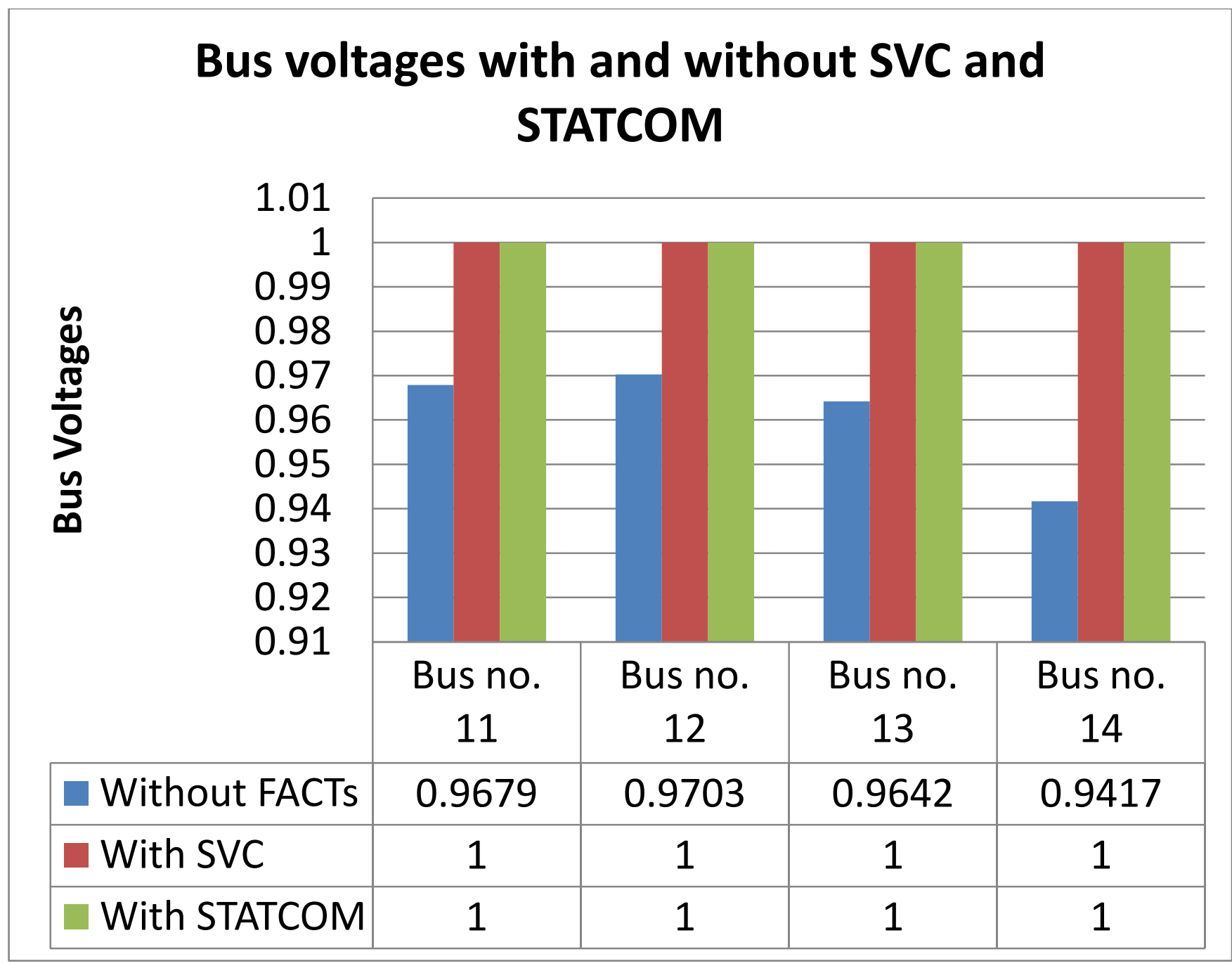

Figure 3.2 Bus Voltages with and without SVC and STATCOM 